\title{
The effect of change in body orientation upon the perceived direction of autokinesis
}

\section{LEONARD BROSGOLE and KAREN $H$. HANSEN, St. John's University, Jamaica, N.Y. 11432}

The egocentric upright was separated from the spatial vertical by rotating the $O$ $90 \mathrm{deg}$ to the right and left. The primary direction of autokinesis shifted in accord with the changes in body tilt. Therefore, it was concluded that the direction of apparent motion is egocentrically determined.

Several investigators have attributed autokinesis to an apparent subject-relative shift in the location of an isolated visual stimulus, initiated by a change in the felt position of the body (Brosgole, 1967; Brosgole \& Cristal, 1967; Brosgole, Cristal, \& Carpenter, 1968; Glick, Wapner, \& Werner, 1965; Jordan, 1967). Since phenomenological data was obtained from Os fixed in an upright position, it has not been demonstrated clearly that the direction of subjective motion is referenced to the egocentric coordinate system, as opposed to the memory image of the visual surround.

In the following experiment the environmental vertical was separated from the egocentric upright by rotating the body $90 \mathrm{deg}$ to the right and left. As the midsagittal plane no longer coincided with the main axis of the surround, as well as the gravitational vertical, it was possible to ascertain which served as a primary frame of reference in determining the direction of autokinesis. Such was the purpose of this current endeavor.

\section{APPARATUS}

The autokinetic stimulus consisted of a $1 / 2$-in. diam sphere of light of extremely low intensity. It was uniform in appearance and adjustable vertically. This permitted it to be aligned with the eye level position.

In order to ascertain the perceived direction of autokinesis, $\mathbf{S}$ was provided with a 360-deg protractor containing a pointer which pivoted about its center. $S$ indicated the direction of autokinesis by tactually rotating the pointer.

The device was mounted on a wooden base. A representation of a human head was affixed to this stand, so as to face in the same direction as S's head. This provided S with a vital cue as to the orientation of the inst rument when making his judgments.

\section{PROCEDURE}

The experiment, consisting of three conditions, took place in total darkness with $S$ located 54 in. from the autokinetic stimulus. In the first condition, $\mathbf{S}$ was seated erectly. He was instructed to fixate the target, placed at eye level, and to report the onset of autokinesis. Once having done so, he was permitted to observe the apparent movement of the stimulus for $10 \mathrm{sec}$. The target then was extinguished and the recording device was handed to $\mathrm{S}$. He was told to rotate the pointer to that spatial location in which the autokinetic stimulus had last appeared. The room lights then were turned on in order to record S's response. S was allowed to keep his eyes open, thereby enabling him to reestablish the location of his body relative to the room. The position of the pointer was randomly changed before the beginning of the next trial. The procedure continued for 15 trials. The first 5 were considered practice trials and, therefore, omitted in the analyses of the data.

The second condition was identical to the first, except that $S$ now reclined upon a cot on his left side. The target was set so as to be perpendicular to the nasion. In Condition 3 , S's body was tilted 90 deg to the right. The order of the three conditions was varied from $S$ to $S$.

\section{SUBJECTS}

Seven males and one female participated in this study. Ranging in age from 18-52, their mean age was 25.5 years. They were all undergraduate students who were naive as to the purpose of the experiment.

\section{RESULTS AND DISCUSSION}

A total of 80 judgments were obtained under each condition of viewing, i.e., 10 responses per $\mathbf{S}$. When sitting erect (Condition 1), 67 responses were up or to the north; 4 were to the right, or east; 5 were downward or south; and 4 were to the left, or west.

With the body rotated $90 \mathrm{deg}$ to the left, in Condition 2, 17 responses were objectively north, 8 were east, 8 were south, and 47 were west. The third condition elicited 14 north judgments, 55 east, 3 south, and 8 west.

In order to evaluate the data statistically, each spatial direction was assigned a different numerical weight. 1 Thus, north, east, south, and west received a weight of 14, respectively. By multiplying the number of judgments in each direction by its appropriate value, a single weighted score was obtained for $S$ under each condition. Accordingly, it was possible to compare S's performance across treatments.

The Friedman two-way analysis of variance indicated that the three conditions differed reliably $\left(\chi \mathrm{r}^{2}=7.56, p<.05\right.$, df $=2$ ). According to the Wilcoxon test, Condition 1 differed significantly from 2 ( $\mathrm{T}=0, \mathrm{~N}=6, \mathrm{p}<.05$ ), as well as $3(\mathrm{~T}=1$, $\mathrm{N}=7, \mathrm{p}<.05)$. Conditions 2 and 3 also differed on the $5 \%$ confidence level $(T=2$, $\mathrm{N}=7$ ).

These findings show that rotating the body has a substantial effect upon the perceived direction of autokinesis. The course assumed by an apparently moving stimulus obviously is not initiated by a phenomenal position change relative to some external frame of reference. The northerly movement predominantly seen in the sitting position, then, was referred neither to the main axis of the laboratory nor to the force of gravity acting upon the body.

Accordingly, the data were again evaluated. This time the weights were assigned in terms of egocentric north, south, etc. The differences between treatments now were not significant according to the Friedman two-way analysis of variance $\left(\mathrm{xr}^{2}=1.94\right.$ $\mathrm{df}=2)$. This demonstrates that the body itself was used as a primary frame of reference. What has been called northerly movement, then, more properly is motion toward and above the head. The same interpretation applies to the remaining spatial coordinates. Therefore, it would seem appropriate to conclude that the direction of autokinesis is egocentrically determined.

\section{REFERENCES}

BROSGOLE, L. Induced autokinesis. Perception \& Psychophysics, 1967, 2, 69-73.

BROSGOLE, L., \& CRISTAL, R. M. Vertically induced autokinesis. Psychonomic Science, 1967, 7, 337-338.

BROSGOLE, L., CRISTAL, R. M., \& CARPENTER, $O$. The role of eye movements in the perception of visually induced autokinesis. Perception \& Psychophysics, 1968, 4, 123-124. GLICK, J. A., WAPNER, S., \& WERNER, H. Some relations between autokinetic motion and space localization. Acta Psychologica, 1965, 24, 41-48.

JORDAN, S. Autokinesis and felt body position. Unpublished doctoral dissertation, New School for Social Research, June 1967.

\section{NOTE}

1. The authors are indebted to Dr. Robert Zenhausern for suggesting this method of data reduction. 